\title{
ADOLESCENT FATHERS: EXPLORING THEIR PERCEPTIONS OF THEIR ROLE AS PARENT
}

\section{Yeukai Chideya, Fatima Williams}

\section{INTRODUCTION}

Teenage pregnancy is one of the socio-economic challenges which South Africa faces, with $35 \%$ of young women under the age of 20 falling pregnant or having had at least one child (Jewkes, Vundule, Maforah \& Jordaan, 2001:733). Research has also highlighted that African youths lack access to sexual health information and services, and this makes them more vulnerable to engaging in risky sexual activity (Ashford, 2000; Bezuidenhout, 2004; Osei-Hwedi \& Namutosi, 2004). In trying to address this challenge most of the focus has been on adolescent mothers, while the needs and experiences of adolescent fathers have been neglected. Adolescent fathers, like their female counterparts, also have to work through their developmental tasks while at the same time trying to adjust to their role of being a father. It is essential that the experiences and perceptions of adolescent fathers be understood as this knowledge can be utilised in the design of appropriate support programmes or measures for these fathers.

\section{THEORETICAL BACKGROUND}

\section{Fatherhood}

Fatherhood is a social, human and cultural role, whose significance changes over time and the content of the role also shifts (Richter \& Morrell, 2006) This results in the expectations of fatherhood and its practices becoming more varied and less defined (Forste, Bartkwoski \& Jackson, 2009). Males are left to define their own identity and meaning as fathers as a result of the decline in the consensus regarding fatherhood and also the lack of clear cultural norms to guide them (Forste et al., 2009). One can argue that this ambiguity heightens the challenge of adolescent fathers whose major developmental task is to form an identity as an individual.

Historically, it has been vital for fathers to be responsible for, and particularly to be able to provide for, the needs of their children. The dissimilarities in the socio-economic background of men's lives means that there are diverse opportunities or limitations for them in creating a significant definition of fatherhood. Men who earn a low income face a unique challenge in building a feasible identity as a father. Although the breadwinner ideal is no longer as central as it was before, its historical impact may lead low-income fathers to view themselves as insufficient providers for their children (Forste et al., 2009).

In South Africa a definition of a good father might put emphasis on accepting responsibility for the paternity, taking care of the child and being a good role model. Even in cases where the fathers are low-income earners and fail to meet the provider role, men still hold onto the belief that being a good man entails being a good father 
(Richter \& Morrell, 2006). The expectation that society puts on a father to become a provider results in adolescent fathers emphasising and making their financial presence in their children's lives the main feature of fatherhood. Impoverished South African adolescent fathers face negative consequences in trying to meet this expectation as their low socio-economic background and unemployment militate against a continuous financial involvement in their children's lives (Swartz \& Bhana, 2009).

\section{ENVIRONMENTAL FACTORS WHICH IMPACT ON ADOLESCENT FATHERS}

\section{Poverty}

In South Africa poverty, unemployment, low levels of education and overcrowding appear to be linked to higher levels of adolescents' sexual activity and to adolescent childbearing (Peltzer, Pengpid \& Mashego, 2006; Preston-Whyte \& Allen, 1992; Thornberry, Smith \& Howard, 1997). This is mainly due to the escalating rate of poverty and inequality in the country, where the poor are prevented from moving above the poverty datum line because of lack of participation in the economy and labour market (Everatt, 2000). Adolescents seem to turn to engaging in sexual activities as a way of forgetting their circumstances and an increase in sexual activity is seen as a way of achieving immediate short-lived pleasure (Bezuidenhout, 2004).

The critical developmental task of all children who have suffered racial discrimination appears to be the acquisition and internalisation of a positive identity (Bezuidenhout, 2008). Adolescents who come from a lower socio-economic background are thus at a higher risk of becoming adolescent parents, as they relate more to their sexual identity which they seem to have "control" over than their social or racial identity which is bestowed upon them by birth.

However, it should also be noted that the "double bind" for adolescent males is that, although their poverty results in their becoming fathers and finding meaning in their lives, it may also lead to their being unable to support their children financially. Inability to be the breadwinner for his child has implications on the sense of self of the adolescent father (Glickman, 2004). This financial constraint usually makes many young males initially deny responsibility for paternity because of their inability to take care of the child (Barker, 2003).

\section{Culture}

Culture is another factor which can make adolescent males vulnerable to becoming fathers in their adolescence. Boys are generally socialised to produce, perform and achieve, and this tendency has great implications for sexuality and reproductive health (Barker, 2003). Young males often view sexual initiation as a way of proving their manhood and gaining status in their peer group (Barker, 2003). This has resulted in risky premarital sex during their adolescence and in some cases resulting in their impregnating their sexual partner. Preston-Whyte and Zondi (1992) argue that African fathers seem to actually encourage their adolescent sons to experiment sexually regardless of their tough stance against premarital pregnancy. The double standard is revealed when a man's 
daughter falls pregnant and he is infuriated, yet when his son impregnates a girl, he may be secretly and even openly pleased. Adolescents are therefore caught in a complex circle of pressures and counter pressures, and the consequence seems almost unavoidable - teenage pregnancy (Preston-Whyte \& Zondi, 1992).

Society focuses more on masculinity than on the emotional state of the adolescent fathers. This emotional constraint can discourage these young fathers from looking for help during the crisis of an unplanned pregnancy (Kiselica, 1995). They might avoid from seeking assistance from their family or community members as a way of proving that they are man enough to handle the unexpected pregnancy.

In many cultural settings boys are not physically or emotionally close to their male role models (Barker, 2003). These role models, who are older men, are the ones who are expected to be teaching and sharing their knowledge of fatherhood with adolescent fathers. But because of the emotional and physical distance between them, adolescent fathers are without the much-needed support to see them through their transition from being a child to becoming a father in their adolescence.

\section{Family factors}

Themes that tend to recur in teenage pregnancy studies revolve around what is termed in the literature as a "poor home background", in particular "a lack of parental interest and control" and poor communication between parents and their children on sexual issues (Preston-Whyte \& Allen, 1992). The adolescent's relationship with his parents influences his adjustment to parenthood. The support adolescent fathers received from their mothers acted as a buffer against stress and adolescent fathers attribute their mothers' roles in their lives as enabling them to become good fathers. However, the double bind associated with this support was that it could become too overbearing when the mothers took too much responsibility for their child, in effect hindering them from positive parental involvement (Fagan, Bernd \& Whiteman, 2007; Swartz \& Bhana, 2009).

Most men have lasting images and fantasies of their father and these can influence how an adolescent father approaches fatherhood (Kiselica, 1995). Adolescent fathers use their experiences with their own fathers as a sort of benchmark as to how they would approach their role as father (Glickman, 2004).

\section{Peer group}

The adolescents' strong need to be liked by their peers and to be part of a group can result in their engaging in sexual behaviours, and also express the sexual attitudes that they view as being characteristic of their admired hero (Bezuidenhout, 2004) and there are also the strong effects of same-sex pressure to be sexually active (Biddecom \& Balikana, 2003).

The male peer group is the setting where adolescents "try out and rehearse macho roles" and the street-based, male peer group has the authority that determines behaviours that are worthy of being called manly (Barker, 2003:115). If the perceived hero's sexual behaviour is risky - for instance, having many sexual partners - then the male 
adolescent will follow suit in order to be like their role model. Unlike adolescent mothers, adolescent fathers might long to become parents for reasons that are selfserving such as gaining status among their peers. Thus the peer group begins to take over the influential role the family has been playing since childhood (Miller, 1997).

South African adolescents are most likely to engage in risky sexual behaviour because they embrace the "romantic love" regime which asserts that sexual activity is acceptable at any age as long as you are in love and that there is no need to use protection (Peltzer et al., 2006). This belief amongst peers makes adolescents vulnerable to pregnancy and sexually transmitted infections, as they overlook the importance of protection, use of contraception and the possibility of the partner being unfaithful.

\section{Research questions}

- How do adolescent fathers from previously disadvantaged backgrounds feel about having become a parent?

- What are the self-perceptions of adolescent fathers from previously disadvantaged backgrounds?

- What do these adolescent fathers think fatherhood entails?

- Which factors influenced these adolescent fathers' perceptions of what fatherhood entails?

- What factors make adolescent males from previously disadvantaged backgrounds vulnerable to becoming fathers in their adolescence?

- What has been the perceived impact of being a parent on adolescent fathers from previously disadvantaged backgrounds?

\section{METHODOLOGY}

This research was an exploratory qualitative study in which the aim was to gain knowledge from adolescent fathers about their perceptions of their new role of fatherhood. In the South African context adolescent fathers' perceptions of fatherhood have not been recorded or investigated in depth. An exploratory research method was used as it allowed the researchers to gain insight into and comprehension of a relatively new topic of research in the South African context. The exploratory method also allowed data to be obtained in an open, flexible and inductive manner.

Ten face-to-face interviews were conducted and each interview lasted for an hour. The interviews were conducted in Hanover Park, Khayelitsha, Samora Machel and Gugulethu (these areas are townships in Cape Town). Face-to-face interviews were conducted as they had an advantage of building rapport with the participants.

Qualitative interviews also "attempt to understand the world from the participant's point of view, to unfold the meaning of people's experiences [and] to uncover their lived world prior to scientific explanations" (Greeff in De Vos, Strydom, Fouche \& Delport, 2011:341). An in-depth interview is more concerned with the process by which the content of the data being provided by the research participants has come into being 
(Babbie \& Mouton, 2005). Hence the in-depth interview focused on the way the adolescent fathers came to hold such perceptions about their new role of parenthood.

\section{SAMPLING}

Non-probability purposive sampling was used in that it targeted, purposefully and specifically, adolescent fathers from previously disadvantaged communities in Cape Town. In this type of sampling the sample is made up of elements that have most of the characteristics and are representative of the population the researchers want to investigate (Strydom in De Vos, et al., 2011). In this instance, the researcher purposively chose to interview 10 adolescent first-time fathers who have children under the age of 3 years and were between 12 to 20 years. The sampling approach also targeted adolescent first-time fathers living in disadvantaged areas.

In order to gain access to potential participants, organisations that work with adolescents were identified and approached. The researcher also approached schools in townships to try and obtain participants. The researcher had great difficulty in obtaining a sample, despite enlisting the help of organisations and schools working with adolescents to locate participants. Some of the potential participants were too scared to participate as they suspected that the researcher was an official who would prosecute them for nonpayment of maintenance. Despite reassurances to the contrary, they did not want to participate in the study. Others were embarrassed to openly admit that they were fathers. There are several other reasons why it is difficult to obtain data on adolescent fathers. Some of the reasons include the fact that research on adolescent parenthood in general focuses more on the role of the mother. Another reason is that it is almost impossible for national surveys to assess if an adolescent male has fathered a child unless he willingly admits the fact to the survey taker (Adams, Pittman \& O'Brien, 1993).

\section{FINDINGS}

The findings will be presented using the research objectives as headings.

\section{HOW ADOLESCENT FATHERS FEEL ABOUT HAVING BECOME A PARENT?}

The participants described a range of feelings that reflected how they felt about being a parent. These feelings were mainly based on the impact of their own perceptions of being a parent and the reaction of their family and peers to their being fathers in their adolescence.

\section{- Feelings of pride}

Most of the participants were proud that they were now fathers as they viewed it as a reflection of their manhood. Becoming a father made these adolescent males feel proud as they were considered culturally as being men, not just young boys.

\section{- Feelings of ambivalence}

Some of the unemployed participants were ambivalent about being a father. This was because of their fear of the responsibility that comes with having a child, as their parents 
had withdrawn their financial support because the adolescent fathers were now considered to be men who should take care of their own families.

\section{- Feelings of guilt}

Several of the participants felt guilty for becoming a father in their adolescence, mainly because of their inability to provide for their children. This finding is supported by Glickman (2004), who states that adolescent males are in a particularly vulnerable state as young fathers who are working through adolescence and dealing with issues of self and identity. Inability to be the breadwinner for their children has implications for the sense of self of the adolescent fathers.

\section{WHAT DO ADOLESCENT FATHERS THINK FATHERHOOD ENTAILS?}

Participants' responses on what they thought fatherhood entails ranged widely. This is a result of males being left to define their own identity and meaning as fathers because of the decline in the consensus on what constitutes fatherhood. There is also a lack of clear cultural norms to guide them (Forste et al., 2009). Below are the perceptions of the adolescent fathers.

\section{- Role of a provider}

The majority of participants mentioned that they understood that being a father meant that one needed to work so that they will be able to provide for the material needs of the child. The research finding highlights how fatherhood is associated with the ability to provide for the material needs of your child. This finding confirms that their perception of the provider role still has a major effect on how the participants measure their success as a father and also what they think fatherhood entails.

\section{- Role of nurturer}

Findings in this research show that some of the participants have willingly taken on the nurturing role and find pleasure in performing duties that were traditionally assigned to mothers.

Several of the participants said their understanding of fatherhood was that the father had to be a nurturer and take up nurturing roles that are usually assigned to only mothers. These roles included babysitting, feeding, changing nappies and waking up during the night to attend to their children's needs.

\section{- Acting as a role model to the child}

Some of the participants highlighted that they understood fatherhood entailing the man being a role model to his children. This included providing guidance and being actively involved in the child's life. The finding indicated how some adolescent fathers viewed the importance of fathers living a life which is exemplary to their children, and creating a good life for them. The literature confirms that in South Africa a definition of a good father might put emphasis on accepting responsibility for paternity, taking care of the child and being a good role model. In communities and societies which are characterised by poverty and limited resources, men are the main source of income in a family and a 
good father in such a context does his very best to secure the life prospects of his child (Morrell, 2006).

\section{WHAT FACTORS MAKE ADOLESCENT MALES VULNERABLE TO BECOMING FATHERS IN THEIR ADOLESCENCE?}

In this research adolescent fathers described how influence from their peers had made them vulnerable to becoming parents in their adolescence.

\section{- Influence of peers}

\section{- Peer pressure to become sexually active}

The findings of this research demonstrate the impact peer pressure had on the participants to engage in sexual activity and how this then resulted in their becoming parents. The majority were pressurised by their peers to engage in sex because these peers were sexually active.

\section{- Influence of friends with babies}

Some participants mentioned that their friends had treated them differently prior to their becoming fathers, because they were the only ones who were not fathers in the peer group. Once they became fathers, they could finally identify with their peers. According to Miller (1997), unlike adolescent mothers, adolescent fathers might long to become parents for reasons that are self-serving, such as gaining status among their peers. The research findings indicate that these participants' self-esteem was boosted when their peers stopped ridiculing them for not having children once they also became fathers.

\section{- Misconceptions about the use of contraception}

Another factor evident in the study which made participants vulnerable to becoming parents was incorrect information on the use of contraception. Most of the participants highlighted that the pregnancy was unplanned and they had tried to prevent it. The research results indicate that some participants did have knowledge about what contraceptives are, but did not understand how they are used or the need to use them properly to avoid pregnancies. There was also the belief that if the partner is the only one with whom they are in a relationship, there was no need to use condoms. This belief has made them vulnerable to impregnating their partners again and also to sexually transmitted infections, because they engaged in risky sexual behaviour.

\section{- Misconceptions about safe sex}

Some participants argued that they are still not using any condoms because they are only having sex with their partner; that this highlights that they are still vulnerable to impregnating their partners again as they are still not using condoms. The literature highlights that South African adolescents are most likely to engage in risky sexual behaviour because they embrace the "romantic love" regime which asserts that sexual activity is acceptable at any age as long as you are in love and there is no need to use protection (Peltzer et al., 2006). 


\section{WHAT IS THE PERCEIVED IMPACT OF BEING A PARENT ON ADOLESCENT FATHERS?}

The impact of adolescent fatherhood on adolescent fathers is subjective and depends on the background that they come from. Participants described a range of ways in which their lives had changed since they learnt that they were going to become fathers. These include: behavioural changes, their family's response to the pregnancy, having to work part time to earn an income to take care of their child, becoming stressed as a result of the new responsibilities, and having low self-confidence because of feelings of shame at having a child in adolescence.

\section{- Impact on behaviour}

The issue of behaviour was an interesting finding in this research as it revealed two contradictory consequences. Some participants highlighted that parenthood had made them become more responsible and focused on building a positive life for themselves and their children. On the other hand, some participants revealed that parenthood had forced them into engaging in illegal activities as a way of earning an income to provide for their children.

\section{- Positive behaviour change}

Most of the participants described how their behaviour changed for the better from the time they realised that they were to become fathers. The finding shows how becoming a father in their adolescence resulted in the participants changing their behaviour to become more positive and constructive through the realisation that they now had a child who was dependent on them and looked up to them.

\section{- Delinquency}

Some of the participants disclosed that their inability to find permanent employment had forced them to become involved in illegal means of making money. One of them further pointed out that he was also abusing substances as a way of numbing the stress that comes with being an adolescent father. As noted above, this finding contradicts the finding which demonstrated that becoming a parent had a positive impact on the adolescent father. Results from this research show how unplanned fatherhood has led some participants into engaging in illegal activities as a means to support their children.

\section{- Response of parents}

The participants gave different descriptions of how their parents' response had impacted on their new role of being a parent. Once again there were contradictory findings with some parents continuing to financially support adolescent fathers, while in other families parents had withdrawn the privileges of the participants.

\section{- Continued support from family}

The majority of the participants highlighted that their parents continued to support them materially and were also helping them take care of their children. This continued support had acted as a buffer against the harsh reality of the consequences of adolescent fatherhood. The finding reflects how some participants are not carrying the full weight 
of responsibilities that comes with fatherhood as a result of the support that their parents are giving them. This has given them an opportunity to gradually transition from adolescence to fatherhood successfully. However, this research finding shows that the continued support by parents can also become a hindrance to participants' involvement in their own child's life. This overbearing parental response can also make adolescent fathers vulnerable to fathering other children in their adolescence as they have not faced the full consequences of their past mistakes.

\section{- Withdrawal of privileges}

Some participants expressed sadness over how life changed when they impregnated their partners and their parents withdrew the privileges they used to enjoy. The parents rechannelled the money they used to spend on the participants to promote the welfare of the children they had fathered.

\section{- Part-time work}

Another factor which emerged in terms of the impact of fatherhood on the adolescent was the need to find part-time work as they were still attending school. Most of the participants described the attempts that they had made and were making in trying to earn an income for them to provide for their children's basic needs. From the findings it is evident how adolescent fathers have had to do part-time work to ensure that they are able to fulfil the expectations of the provider role.

Hence being an adolescent father results in the shifting of focus from just acquiring an education to also finding opportunities to earn an income.

\section{- Stress}

Some participants indicated that they have been stressed since the time they learnt that their partners were pregnant. This stress was mainly caused by the realisation of their incapability to provide for their children.

\section{- Decrease in self-confidence}

Several participants highlighted that their self-confidence had decreased from the time they became adolescent fathers. They attributed this to their fear of being judged by other people for having a child in their adolescence. Adolescent fathers face a great challenge in forming an identity that makes them fit in both with their peers and older fathers.

\section{DISCUSSION}

The main theme of the findings of this research has been the quest of adolescent fathers in trying to fulfil the provider role. Financial independence and security are some of the main determinants of how adolescent fathers feel about being a parent. Although adolescent fathers are generally proud of being a parent and happy about the independence that comes with it, they are caught in the dilemma of finding ways to provide for their child. This dilemma is the result of their still being dependent on their own parents while at the same time having to provide for their children. This highlights how going through two major developmental phases (adolescence and fatherhood) 
concurrently results in role confusion, which means that adolescent fathers struggle to amalgamate their two identities of being a child and a parent. Being able to provide for one's child is viewed as a symbol of being a good father and failure to do so results in shame and guilt.

The adolescent fathers experienced a range of emotions about becoming a parent. These included feelings of pride, ambivalence and guilt. These feelings were mainly influenced by the reaction from significant others on their new role of being a parent and also how they (adolescent fathers) perceived their ability to provide for their children. It is clear that becoming a parent results in adolescent fathers feeling proud that they are now considered as being men by significant others. However, with manhood comes responsibilities such as being able to take care of and provide for one's family.

Adolescent fathers' responses indicated that they had a positive self-perception and future outlook, regardless of their being fathers in their adolescence. Participants did highlight the challenge of not being able to fully meet the expectations of fatherhood, which they described in their view of what it means to be a man. However, this had not deterred them; instead it had motivated them to work harder towards creating a good future for themselves and their children. These fathers have shown resilience and they have positive goals for the future. Fatherhood seems to make them realise that their lives are no longer their own and that they are accountable for the care of their children.

Although participants had different thoughts on what fatherhood entails, they were all focused on being able to take care of their children. They understood fatherhood as entailing a provider role, a nurturer and being a role model to their child. These adolescent fathers are growing up in a patriarchal society which emphasises and socialises them on the importance of the provider role in fatherhood. Fulfilling this expectation is the greatest challenge that the adolescent fathers experience. This shows how society has played an important role in defining what fatherhood entails for the participants, as their thoughts on this topic are in line with societal expectations.

The fatherhood role is evolving from being just being a provider to also including being the role model and nurturer, and it is interesting to note that some adolescent fathers have willingly taken up the nurturer role regardless of being mocked by their peers for doing so. Being a male nurturer does not fit into the values and beliefs of a patriarchal society, but this has not hindered the adolescent fathers from playing this role. In fact they enjoyed spending such intimate time with their children.

Adolescent fatherhood can impact both positively and negatively on one's behaviour. The context that the adolescent fathers come from will influence how they will respond to their new role of being a parent. Adolescent fathers' responses showed that parents and peers have influenced their perception of what fatherhood entails. The adolescent fathers' perceptions on fatherhood have been shaped differently by the relationship they have with their fathers, the support from their mothers and advice from friends. Not all experiences that the adolescent fathers had with their parents were positive.

Adolescent fathers who come from families who can afford to support both them and their child are most likely to change their behaviour for the better because of the support 
they are receiving. However, adolescent fathers who come from families who cannot afford to support both them and their child are most likely to view illegal activities as a means of earning an income.

A finding of this research which contradicts the literature is how adolescent fathers have been inspired to become good parents despite their negative experiences with their absent or passive fathers. Growing up without an active father affected the adolescent fathers and made these particular participants desire to arrange things differently for their own children. Their experience with their fathers made them aware of the different roles that a father should play. These roles included being there for one's child, and providing for and taking care of him or her, something that they (the adolescent fathers) did not have the chance to experience. Thus instead of following the negative footsteps of their own fathers, the adolescent fathers seem to rework their issues with their fathers through their own relationships with their children.

The culture of the peer group played a big role in these adolescent fathers adjusting to their new role of fatherhood as it dictates that being a father is one way of becoming a man. All participants described how peer pressure had made them vulnerable to becoming fathers in their adolescence. They succumbed to peer pressure as a way of wanting to be accepted and identify with their peer group. The adolescent fathers had based their decisions on sex and contraception on what their misinformed peer group had suggested. These fathers only realised the limitations of the information they had been given about sex by their peers after they had impregnated their partners. Their immediate desire was to please their peers and also to become sexually active like them, and they did not consider the effect of this decision on them and their partner. Adolescent fathers highlighted that they were only accepted and respected by their peers with babies only when they too became fathers. The research findings indicate that these participants' self-esteem was boosted when their peers stopped ridiculing them for not having children once they also became fathers.

\section{CONCLUSION}

There is a great need for further research in the area of adolescent fatherhood. The challenge that the researcher experienced in trying to obtain a sample is an indicator of how adolescent fathers have been alienated. The personal needs of adolescent fathers, and the impact of fatherhood on their lives, are areas that the researcher believes need the most focus. Being an adolescent father in a developing country which has a strong cultural belief system, and coming from a low socio-economic background present these fathers with unique challenges that need to be further researched. Knowledge gained from such studies could help relevant departments develop programmes to meet the needs of adolescent fathers, and also ensure that they are recognised as a vulnerable group like their female counterparts.

\section{REFERENCES}

ADAMS, G., PITTMAN, K. \& O'BRIEN, R. 1993. Adolescent and young adult fathers: problems and solutions. In: LAWSON, A. \& RHODE, D.L. (eds) The politics of 
pregnancy: adolescent sexuality and public policy London: Yale University Press, 635-669.

ASHFORD, L. 2000. Social marketing for adolescent sexual health. Washington DC: Population Reference Bureau.

BABBIE, E. \& MOUTON, J. 2005. The practice of social research. Cape Town: Oxford University Southern Africa.

BARKER, G. 2003. Engaging adolescent boys and young men in promoting sexual and reproductive health: lessons, research, and programmatic challenges. Chapter 6. In: Adolescent and youth sexual and reproductive health: charting directions for a second generation of programming - background documents for the meeting. New York: Population Council, 109-153. [Online] Available: http://www.pop-council.org/ pdfs/AYSRH/6.pdf [Accessed: 15/03/2010].

BEZUIDENHOUT, F. (ed). 2004. A reader on selected social issues $\left(3^{\text {rd }}\right.$ ed). Pretoria: Van Schaik Publishers.

BEZUIDENHOUT, F. (ed). 2008. A reader on selected social issues $\left(4^{\text {th }}\right.$ ed). Pretoria: Van Schaik Publishers.

BIDDECOM, A. \& BAKILANA, A. 2003. Transition into sex, parenthood and unions among adolescents and young adults in South Africa. Cape Town: National Institute of Child Health and Human Development.

DE VOS, A.S., STRYDOM, H., FOUCHÉ, C.B. \& DELPORT, C.S.L. 2011. Research at grass roots - for social sciences and human service professions. Pretoria: Van Schaik Publishers.

EVERATT, D. 2000. The dead decade? Youth in post apartheid South Africa. Development Update, 3(2):1-39.

FAGAN, F., BERND, E. \& WHITEMAN, V. 2007. Adolescent fathers' parenting stress, social support and involvement with Infants. Journal of Research on Adolescence, 17(1):1-22.

FORSTE, R., BARTKOWSKI, J.P. \& JACKSON, R.A. 2009. "Just be there for them": perceptions of fathering among single, low-income men. Fathering, 7(1):49-69.

GLICKMAN, H. 2004. Low income fathers: contexts, connections \& self. Social Work, 49(2):195-206.

JEWKES, R., VUNDULE, C., MAFORAH, F. \& JORDAAN, E. 2001. Relationship dynamics and teenage pregnancy in South Africa. Social Science and Medicine, 52(5):733-744.

KISELICA, M.S. 1995. Multicultural counselling with teenage fathers. A practical guide. Multicultural aspects of counselling. Series 6. London: Sage Publications.

MILLER, D.B. 1997. Adolescent fathers: what we know and what we need to know. Child and Adolescent Social Work Journal, 14(1):55-69. 
MORREL, R. 2006. Fathers, fatherhood and masculinity in South Africa. In: RITCHER, L. \& MORRELL, R. (eds) Men and fatherhood in South Africa. Cape Town Human Science Research Council, 13-25.

OSEI-HWEDIE, K. \& NAMUTOSI, R. 2004. Condom use \& HIV/AIDS: precautionary behaviour amongst Botswana youth. Social Work, 40(2):193-205.

PELTZER, K., PENGPID, S. \& MASHEGO, T.A. 2006. Youth sexuality in the context of HIV/AIDS in South Africa. New York: Nova Science Publishers.

PRESTON-WHYTE, E. \& ALLEN, J. 1992. Teenage pregnancy in the coloured community. In: BURMAN, S. \& PRESTON-WHYTE, E. (eds) Questionable issue: illegitimacy in South Africa. Cape Town: Oxford University Press, 208-225.

PRESTON-WHYTE, E. \& ZONDI, M. 1992. African teenage pregnancy: whose problem? In: BURMAN, S. \& PRESTON-WHYTE, E. (eds) Questionable issue: illegitimacy in South Africa. Cape Town: Oxford University Press, 226-245.

RITCHER, L. \& MORRELL, R. (eds). 2006. Men and fatherhood in South Africa. Cape Town: Human Sciences Research Council.

SWARTZ, S. \& BHANA, A. 2009. Teenage Tata: voices of young fathers in South Africa. Cape Town: Human Sciences Research Council.

THORNBERRY, T.P., SMITH, C.A. \& HOWARD, G.J. 1997. Risk factors for teenage fatherhood. Journal of Marriage and the Family, 59(3):505-521.

Ms Yeukai Chideya (Postgraduate student); Ms Fatima Williams, Department of Social Development, University of Cape Town, Cape Town, South Africa. 